\title{
Knowledge-Yielding Communication
}

\section{$\underline{\text { Andrew Peet }}$}

\section{Introduction}

Linguistic communication allows for the acquisition of testimonial knowledge. This is one of its central functions. ${ }^{1}$ Thus, a central task for the theory of linguistic communication is to explain how it is that, through the interpersonal exchange of auditory, visual, and tactile stimuli, the communicative preconditions for the acquisition of testimonial knowledge (or, the conditions for 'knowledge-yielding communication') regularly come to be satisfied. Yet there is, at present, no satisfactory account of knowledge-yielding communication. Thus, this central success condition for linguistic theorizing is currently opaque, and we are left with an incomplete understanding of testimony, and communication more generally, as a source of knowledge.

It is natural to hold that knowledge-yielding communication occurs whenever two or more interlocutors coordinate on the same proposition or set of truth conditions. However, such coordination can occur as a matter of luck. This is inconsistent with the acquisition of knowledge. Moreover, communication does not always involve the duplication of thoughts. It often involves the quasi-inferential reconstruction of thoughts. This suggests that much communication is approximate, meaning that exact coordination is rare. Yet this does not preclude the acquisition of testimonial knowledge. A natural response to the first problem is to strengthen the conditions on knowledge-yielding communication, holding, for example, that interlocutors must know that they are coordinating on the same contents. ${ }^{2}$ A natural response to the second problem is to weaken the conditions on knowledge-yielding communication, holding that interlocutors need only entertain relevantly similar propositions or sets of truth conditions. These responses pull in opposing directions.

The account presented here resolves this tension by modeling knowledge-yielding communication on knowledge itself. It is argued that knowledge-yielding communication occurs iff interlocutors coordinate on truth values in a non-lucky and non-deviant way. I primarily focus on the anti-luck component of the account here, due to the explanatory work it is able to do.

The paper proceeds as follows: $\$ 2$ clarifies our core question, relating the question of knowledgeyielding communication to the more general task of providing a complete epistemology of testimony. \$3 criticizes the view that knowledge-yielding communication occurs iff interlocutors coordinate on the same content. $\$ 4$ criticizes "similar content" approaches. The critical discussion in $\$ 3$ and $\$ 4$ forms the basis of the positive view, which is presented in $\$ 5$ and $\$ 6 . \$ 5$ presents a pure anti-luck approach. $\$ 6$ explains how the anti-luck approach is incomplete, and provides the formula for completing it. ${ }^{3}$

1 The spread of knowledge is not the only important function of language. Language functions, for example, as a means for social bonding and collective action, and also as a means for degradation, subordination, and control. However, the spread of knowledge is clearly an important function of language. So one central task of the theory of language is to explain how linguistic communication enables the spread of knowledge.

2 Heck (1995) provides a view along these lines, although they merely require knowledge of truth conditions, allowing that interlocutors may entertain propositions containing slightly different senses.

3 A note on methodology before we begin: The argument relies on judgments about cases. Usually these judgments will be 


\section{The Core Question}

Our core question is as follows:

QUESTION: What are the purely communicative preconditions for the acquisition of testimonial knowledge?

This question needs to be clarified. No relation of communication alone will be sufficient for the acquisition of testimonial knowledge. A testimonial exchange could be unproblematic along the communicative dimension, yet still fail to yield testimonial knowledge due, for example, to the speaker's dishonesty, or the audience's lack of trust. When an agent fails to gain testimonial knowledge in such circumstances the communicative preconditions for the acquisition of testimonial knowledge are met. The audience's inability to acquire testimonial knowledge is not explained by any breakdown in communication. We are concerned, in this paper, with the conditions which are met when an audience acquires testimonial knowledge, or when an audience's inability to acquire testimonial knowledge is explained by some non-communicative defect in the exchange. ${ }^{4}$

To get clear on this, it will be instructive to consider some examples:

GOOD: Mary and Petra are both native English speakers. Moreover, they are good friends, and have strong reasons to trust one another. Mary knows that Petra's friend Tom is in town, and she wants to share this knowledge with Petra. So she clearly states to Petra that 'Tom is in town'. Petra hears and understands Mary's assertion. On this basis she comes to believe that Tom is in town.

In this case Petra gains knowledge. Both the communicative and non-communicative preconditions for the acquisition of testimonial knowledge are satisfied. By contrast, consider the following:

BAD: Mary and Petra are both native English speakers. Moreover, they have been friends, and Petra has strong reasons to trust Mary. Nonetheless, Mary has developed a bitterness toward Petra, and wishes to deceive her. Mary believes that Petra's friend Tom is in town, but she doesn't want Petra to know this. So she clearly states to Petra that 'Tom is out of town'. Petra hears and understands Mary's assertion. On this basis she comes to believe that Tom is out of town.

given theoretical support. In particular, I will repeatedly motivate a diagnosis of knowledge or failure of knowledge by considering whether or not a belief is held and true in a non-lucky and non-deviant way. It is an assumption of this paper that knowledge is, roughly, non-deviant non-lucky true belief (where non-deviance is taken to imply justification, and where each clause can be spelled out in different ways, including ways which ultimately refer back to a basic unanalyzable concept of knowledge).

4 It may seem strange to say that 'knowledge-yielding communication' has occurred when knowledge has not been acquired. But 'knowledge-yielding communication' is merely a label. If the reader prefers, they may substitute 'potentially knowledge-yielding communication' as a label for our target concept, and save the label 'knowledge-yielding communication' for the relation as it occurs in communicative exchanges which actually result in knowledge. This labeling convention may, ultimately, be more accurate. However, the convention employed here makes for snappier presentation. 
Here Petra fails to gain knowledge. However, her failure is not due to any breakdown in communication. The conditions for knowledge-yielding communication have been satisfied. Rather, she fails to gain knowledge as a result of Mary's dishonesty. There are also cases where knowledge-yielding communication occurs, but where it is more controversial whether or not knowledge is gained:

CONTROVERSIAL: Mary and Petra are both native English speakers. But they are also strangers. They do not have any particular reasons to trust one another. Mary has just been watching the World Cup, and wishes to spread the word regarding Belgium's surprise victory over Brazil. So, she approaches Petra in the street and states that 'Belgium just beat Brazil in the World Cup'. Petra hears and understands Mary's assertion. Moreover, she does not know much about football, and so lacks any particular reason to doubt Mary's claim. So she comes to believe that Belgium beat Brazil in the World Cup.

Here it is more controversial whether Petra gains knowledge. If we are liberal about the conditions for testimonial knowledge, holding that audiences have a defeasible default right to accept testimony, then we will likely hold that Petra gains knowledge. However, if we hold that positive reasons of trust are required for testimonial knowledge then we will want to deny this. The important thing to note, however, is that even if knowledge is not gained, this failure is not due to a breakdown in communication. If we hold all the other factors fixed, and simply add that Petra does have good reason to trust Mary, then it will be uncontroversial that she gains knowledge. This stands in contrast to cases like the following:

MISCOMMUNICATION: Mary and Petra are both native English speakers. Moreover, they are good friends, and have strong reasons to trust one another. Mary knows that Petra's friend Tom is in town, and she wants to share this knowledge with Petra. So she states to Petra that 'Tom is in town'. Petra mishears Mary's assertion, and takes her to have stated that 'Tom is a clown'. On this basis, she forms the belief that Tom is a clown.

Here, Petra fails to gain knowledge (even if, as it turns out, Tom is a clown). Yet this failure is not due to any dishonesty or unreliability on Mary's part. And Petra's belief is, we may suppose, very well justified. She fails to gain knowledge due to a breakdown in communication. We are concerned in this paper with the conditions which are satisfied in GOOD, BAD, and CONTROVERSIAL, but which are not satisfied in MISCOMMUNICATION.

This can be thought of as follows: in typical cases of testimony, a speaker attempts to represent the world in a particular way. There is some proposition which they attempt to represent as true. Likewise, the audience will represent the speaker as having, through their assertion, represented the world as being a particular way. They will, upon hearing the assertion, enter a state of apparent comprehension which represents the speaker as presenting some proposition as true. ${ }^{5}$ When they come to believe this proposition (and thus, from their perspective at least, accept the speaker's testimony) they will have formed what we may call a "testimonial belief". 6

5 This state of comprehension may be the result of some quasi-inferential process, or it may be a matter of decoding some packaged message. This is a matter with which we need not concern ourselves.

6 Thus, the type of belief we are concerned with relates closely to what Goldberg (2007), following Audi (1997), calls 
In order for a testimonial belief to constitute knowledge, various conditions must be satisfied. For example, the speaker's representational intention, and the audience's representation of the speaker as having presented a particular proposition as true, must be related in the right way. In MISCOMMUNICATION these states are not related in the right way. In GOOD, BAD, and CONTROVERSIAL, they are related in the right way. There is a question regarding what it is for these states to be related in the right way. That is the question which will be addressed in this paper.

The requisite relation might be very strict. For example, it might be held that knowledge-yielding communication requires that the interlocutors coordinate on precisely the same fine grained proposition, and that it be common knowledge that they have succeeded in doing so. Alternatively, they may be quite loose, only requiring, for example, that the interlocutors entertain somewhat similar propositions. However this question is settled, we will not come away with a complete epistemology of testimony. Even supposing that the strictest possible conditions on knowledge-yielding communication are satisfied, an audience may still fail to gain testimonial knowledge upon forming a testimonial belief. For example, we might suppose that in BAD it is mutual knowledge that Mary, through her assertion, represents it as being the case that Tom is out of town. Petra does not gain knowledge in BAD, but this failure is due to Mary's dishonesty. Likewise, we might suppose that it is mutual knowledge in CONTROVERSIAL that Mary represented it as being the case that Belgium beat Brazil. Yet there is still a question to be asked about whether or not Petra gains knowledge.

Thus, issues such as dishonesty and speaker unreliability, (i.e. the usual subject matter of the epistemology of testimony) can be theorized about largely in abstraction from issues to do with communication itself. We can presuppose perfect knowledgeable coordination between interlocutors, and still ask substantive questions about, for example, whether audiences must have reasons to trust a speaker in order to gain knowledge. However, suppose we hold fixed all the factors in a case such that, if perfect knowledgeable coordination has occurred, it will be uncontroversial that testimonial knowledge has been acquired. We can then ask: must perfect knowledgeable coordination occur in order for the audience to gain knowledge? Or is some lesser relation sufficient? A complete understanding of testimony, and communication more generally, as a source of knowledge, requires an answer to this

\footnotetext{
'belief through testimony'. Goldberg and Audi both note that there are cases in which an audience's belief that $p$ is somehow dependent on a speaker's testimony, without in any sense being a testimonial belief. For instance, if a speaker says something in English we may, as a result of our understanding the content of their utterance, come to learn that they speak English. Likewise, if somebody states that they are a baritone in a baritone voice we can learn that they are a baritone without, in any sense, relying on their testimony. This prompts Goldberg to focus on knowledge through testimony, which he defines as "knowledge involving reliable belief in what was attested, formed on the basis of its having been attested" (Goldberg (2007) $\mathrm{p} 15)$. In this paper we are concerned with cases where the audience comes to believe that $p$ on the basis of their representation of the speaker as having presented $p$ as true. This rules out beliefs like the English speaking or baritone beliefs as testimonial. However, it builds in less than the notion of knowledge through testimony: knowledge through testimony requires that the belief the audience forms be in a proposition attested to by the speaker. However, it is unclear precisely what it is for a speaker to attest to a particular proposition. Moreover, it is an open question, at this point in the investigation, whether an audience's testimonial belief must be in a proposition attested to, or rather in a proposition in some sense related to one attested to by a speaker. It may well be that, given the potentially messy and quasi-inferential nature of linguistic communication, true belief through testimony is rare. It may be that most so called 'testimonial knowledge' merely approximates knowledge through testimony. This is an issue which I do not wish to prejudge at this point.
} 
question.

\section{The Simple View}

The simplest response to QUESTION is to hold that knowledge-yielding communication occurs when a speaker performs an assertion intending to communicate some proposition $p$, and the hearer recovers $p$, where propositions are conceived of in a coarse grained manner. Unfortunately, such coordination is not sufficient for knowledge-yielding communication. An obvious fallback would be to require coordination on more fine grained contents. However, as we shall see, there is reason to be skeptical of such approaches. Moreover, we will find that coordination on coarse grained content is also unnecessary for knowledge-yielding communication. By examining these failings of the simple view we are able to identify two seemingly conflicting criteria an account of knowledge-yielding communication must satisfy.

\subsection{Simple Sufficiency}

The simple view's failure to provide a plausible sufficient condition on knowledge-yielding communication is illustrated by cases like the following (originally introduced by Brian Loar (1976), and henceforth referred to as "Loar cases")):

LOAR: Suppose that Smith and Jones are unaware that the man being interviewed on the television is someone they see on the train every morning, and about whom in that latter role, they have just been talking. Smith utters 'He is a stockbroker' intending to refer to the man on the television; Jones takes Smith to be referring to the man on the train. Now Jones, as it happens, has correctly identified Smith's referent, since the man on the television is the man on the train; but he has failed to understand Smith's utterance. Loar 1976: 357.

If the content of "he" is exhausted by its referent then Smith and Jones have the same belief. Thus, on the simple view, knowledge-yielding communication will have occurred. Yet Jones does not gain testimonial knowledge. Loar, who focused on mutual understanding rather than knowledge-yielding communication, concludes that direct reference views must be rejected.

However, Loar's diagnosis can be questioned. Similar cases can be given in which the interlocutors share descriptive modes of presentation. Consider the following case presented by Byrne and Thau (1996).

$7 \quad$ Our core question should be distinguished from that of when we communicate well enough to transmit knowledge. A speaker transmits their knowledge or justification when, in some robust sense, their knowledge or justification becomes the audience's knowledge or justification. Transmission views are highly controversial (see Lackey (1999), MacFarlane (2005), Barnett (2015), Fraser (2016), Peet and Pitcovski (2017), and Leonard (forthcoming) for objections). It is a truism that we have a great deal of testimonial knowledge, so much so that any view of linguistic communication that predicts otherwise should be treated with skepticism. This is not true of transmission based knowledge. Hence the focus on a broader question of knowledge-yielding communication. Our question should also be distinguished from that of the general conditions for communicative success. Communicative success is a multifaceted notion. For example, it is sometimes thought of in terms of knowledge transmission (Evans (1989), Heck (1995)), the enabling of successful action (Paul (1999), Carston (2002), Bezuidenhout (2002)), rational engagement (Heck 2002), or as an intuitive notion (Pagin (2008), (forthcoming)). These distinct notions of communicative success, I believe, require distinct treatments. Here I focus on what I take to be one of the most important notions of communicative success: knowledge-yielding communication. Although, as we will see, there are lessons to be drawn about other forms of communicative success (insofar as they also preclude luck). 
HOSPITAL: A patient checks into hospital and is assigned room 101. Tony dubs him "Winston" and the cognitive value she attaches to the name is: the amnesiac in room 101. Alex is thoroughly unaware that Tony has seen the patient, but by sheer chance she also dubs him "Winston" and attaches the same cognitive value to the name. Alex utters "Winston will never recover" in Tony's presence, and Tony forms the belief she would express by saying "Winston will never recover". Byrne and Thau (1996), p 147.

As Byrne and Thau note, the interlocutors share the same content under the same descriptive mode of presentation, yet testimonial knowledge is not acquired. Thus, sharing descriptive modes of presentation is also insufficient for knowledge-yielding communication. Indeed, the problem is not restricted to referential communication. We can generalize this method of generating cases by having interlocutors luckily coordinate on the meanings of general terms, quantifiers, connectives, or operators. The obvious lesson to draw from these cases is that, firstly, the sharing of coarse grained contents is not sufficient for knowledge-yielding communication, as such coordination can occur as a matter of luck, and secondly that it is not clear the problem can be resolved by adding sense or structure to the thoughts entertained. ${ }^{8}$ The inconsistency of knowledge-yielding communication with luck should come as no surprise, as knowledge precludes luck. ${ }^{9}$ A satisfactory account of knowledge-yielding communication must capture this.

\subsection{Simple Necessity}

We should also be skeptical of the necessity of precise coordination for knowledge-yielding communication. Several otherwise plausible pictures of communication and mental content seem to imply that interlocutors rarely coordinate even on coarse grained propositions. ${ }^{10}$ If any of these views are correct then the simple view sanctions a widespread skepticism about testimonial knowledge. Moreover, it seems antecedently plausible that, within certain bounds, communication is often

8 There are alternative views of sense against which Byrn and Thau's example has less force. For example, if we deny that the aboutness properties of Tony and Alex's "Winston" beliefs are explained by reference to the description they attach to the name, and identify senses with explanations of the aboutness properties of token thoughts (in a manner somewhat akin to Evans (1982)), then we can deny that they each think of Winston under the same mode of presentation. The important point is that, as things stand, Loar cases have little dialectical force against the direct reference theorist. In order for these cases to have force it needs to be established that the elimination of luck requires coordination on senses (of some sort). At this point this has not been shown. We will return to this point in $\ 5.2$ when it will be argued that, in order for communicative luck to be eliminated there must be a robust explanation for the relational fact that the interlocutors' token thoughts share certain aboutness properties. This provides some support for the Fregean thought that communication requires thinking of referents in suitably related ways, although it does not (by itself) require us to build modes of presentation into the contents of the interlocutors' thoughts.

$9 \quad$ It might be objected that in HOSPITAL the interlocutors are not justified in taking their usage to be shared. However, it can easily be modified to account for this. We need merely adjust the case such that each interlocutor has a gettiered belief that their meaning is shared.

10 For example, the radical contextualism of Sperber and Wilson (1986), Bezuidenhout (1997), and Carston (2002). It is also often acknowledged that coordination on finer grained contents is not necessary for successful communication. This claim is held by some fregeans such as Bezuidenhout (1997) and Heck (2002), and several approaches to indexical content (See Weber (2016) for an overview)). I will focus on coarse grained contents, as the failure of coarse grained coordination implies failures of fine grained coordination. 
approximate and loose. If coordination is typically approximate, yet knowledge-yielding communication requires precision, then knowledge-yielding communication will be rare.

Still, this may simply be taken as evidence that communication is typically precise. So I will outline two cases in which an audience forms a non-lucky non-deviant true belief despite failing to coordinate precisely with the speaker. Such cases suggest that exact coordination on coarse grained content is not required for knowledge-yielding communication. Consider the following:

HEIGHT: Branden and Emily are discussing Michael Jordan's height. Branden says 'Michael Jordan is tall'. As it happens Branden and Emily assign slightly different meanings to the word 'tall'. For Branden 'tall' means 'over 1.8 meters', for Emily it means 'over 1.7999999999999999 meters'. So the proposition Emily believes differs from the proposition Branden intends. Still, since Michael Jordan is actually 1.98 meters tall Emily's belief could not easily have been false. The world would have to have been very different for her belief to have been false. Moreover, Branden would not make his assertion in these worlds, as Michael Jordan is not over 1.8 meters tall in these worlds. Thus, it seems that Emily comes to know that Michael Jordan is over 1.7999999999999999 meters in height. ${ }^{11}$

There are two worries one might have about HEIGHT. Firstly, one might worry that no realistic agent would assign 'tall' such a precise extension. This is correct. But it is not clear that this observation can vindicate the simple view. We could, for example, modify the case such that Branden and Emily's uses of 'tall' are indeterminate over slightly different ranges of heights meaning that, at some point, an agent can count as determinately tall for Emily and not for Branden. Such a case would not involve precise coordination. ${ }^{12}$ Yet, if Michael Jordan is safely within the range of "tall" for both Branden and Emily knowledge-yielding communication still occurs. Secondly, one might object on externalist grounds, holding that 'tall' has its extension fixed in the same way for both Branden and Emily by factors beyond their ken. However, it doesn't follow from the core tenants of externalism that 'tall' cannot have a slightly different extension for Emily and Branden. For example, it may be that Emily and Branden are from related but separate linguistic communities which, despite having marginally different patterns of use for the term 'tall', can interact as if they speak the same language. Such a situation is possible, and seems consistent with Emily gaining knowledge.

HEIGHT illustrates that very slight differences in meaning are compatible with knowledge-yielding communication. However, it is worth noting that, in the right conditions, more radical divergence in meaning can also be compatible with knowledge-yielding communication:

BEER: Sam and Marie have organized a party for which they are supplying beer. Some guests

11 The exact meanings assigned by the interlocutors in this case are not essential. In particular we can swap the meanings assigned and gain the same result (as long as we suppose that in the reversed case Branden would, to avoid risk, not predicate tallness of agents who only just count as tall for him). The important fact is that the object of the predication (Michael Jordan) falls safely outside of the margin for error for both interlocutors' uses of “tall”. As a result, Emily's belief is rendered safe.

12 It is not clear in general how introducing indeterminacy makes coordination easier. Indeed, on some ways of modeling indeterminacy (for example in terms of fuzzy meanings) indeterminacy makes precise coordination even harder (MacFarlane (2016)). 
have also brought their own beer. Sam has to leave before the party begins, and returns once it is in full swing. Most of the guests have been sharing their own beer and drinking the beer provided. Sam, upon arrival, approaches Marie and Molly (a guest). He asks them "is there any beer left?" He is interested in whether or not there is any beer at the party -beer he can drink. However, Marie interprets him as asking whether any of the beer they purchased remains. She answers "no, there isn't any beer left", intending to communicate that the beer they purchased has all been consumed. Sam forms the belief that all the beer at the party has been consumed. As it happens, his belief is true. The beer brought by the guests has also been consumed. Molly knows this. She is aware that the guests have been sharing beer, and that Marie and Sam might have their wires crossed. If there was any guest beer left Molly would correct Marie, and let Sam know that there is some remaining beer. However, she says nothing, as she knows that whichever proposition Sam recovered was true.

If it wasn't for Molly Sam would not have gained testimonial knowledge. Marie would have asserted "there isn't any beer left" even if there was some guest beer, in which case Sam would have formed a false belief. This easily could have happened. However, Molly's presence as a member of the group addressed by Sam removes this risk of error. Because of her presence, and her dispositions to correct Marie, Sam could not easily have formed a false belief. The element of luck is eliminated. Moreover, Sam's belief is justified, and there does not seem to be anything deviant about the manner in which it is true. He acquires a true belief as a result of Marie's sincere testimony, his own normally functioning system of comprehension, and Molly's disposition to discharge her discursive responsibilities as a party to the discussion. ${ }^{13}$ So we should conclude that Sam does gain knowledge, and that the simple view is false. $^{14}$

Together, HEIGHT and BEER illustrate that precise coordination is not required for knowledgeyielding communication. If interlocutors entertain similar enough propositions, or the social environment is sufficiently accommodating, knowledge-yielding communication can occur despite divergence in interpretation. This creates a puzzle: In $\$ 3.1$ we observed that precise coordination was not sufficient for knowledge-yielding communication. Something more, such as knowledge of successful coordination, is needed to rule out communicative luck. ${ }^{15}$ However, the observations in $\$ 3.2$ pull us in

13 That interlocutors have such discursive responsibilities is illustrated by the fact that we will generally hold others responsible for failing to correct harmful misunderstandings or false testimony if they are easily able to do so. For an extended discussion of the duty to object to misleading testimony see Lackey (forthcoming).

14 One might object as follows: If asked why he believed that all the beer at the party had been consumed Sam would respond "Marie told me so". However, this is not what Marie intended to tell him. Thus, his belief is based on a falsehood. This objection faces several problems (besides presupposing the impossibility of knowledge from falsehood). Firstly, the question under discussion was that of whether there was any beer left at the party. Marie simply fails to realize this. Insofar was what is said is determined by the question under discussion (Schoubye and Stokke (2016)), or similar factors such as reasonable interpretation, we should say that Marie did (accidentally) assert that there isn't any beer at the party. Thus, we can maintain that Sam's report is accurate. Moreover, Sam is providing a retrospective rationalization of his belief. The actual process by which he formed his belief took place largely at the subpersonal level: Marie uttered the sentence "there isn't any beer left", Sam perceived her utterance, and the sub-personal cogs of interpretation started turning. The output of this process was a representation of the party as lacking beer. Sam's belief state was automatically updated with this representation (since he possessed no defeaters). It is the actual process of belief formation, not the retrospective rationalization, which matters for knowledge. And this process, embedded in this environment, produced a justified and safe true belief. Thus, Sam gains knowledge.

15 Similarly, Loar cases have been used to motivate the need for knowledge of truth conditions (Heck (1995)), or knowledge 
the opposite direction. The simple view is unable to capture the consistency of imprecision with knowledge-yielding communication. In HEIGHT and BEER knowledge of successful coordination failed for the basic reason that the interlocutors did not coordinate successfully. Thus, the simple view is at once overly demanding and insufficiently demanding. A satisfactory approach to knowledge-yielding communication will resolve the apparent tension between its inconsistency with luck, and its toleration of imprecision.

\section{Similar Propositions}

Before moving on to the positive proposal it is worth briefly considering an obvious weakening of the simple view, which may be thought capable of solving the problem of imprecision. According to this weakened version of the simple view knowledge-yielding communication requires only that interlocutors entertain relevantly similar propositions (a similar stance is taken with respect to communicative success by Bezuidenhout (1997), and Carston (2002)).

In light of the preceding discussion it should be clear that content similarity will not suffice for knowledge-yielding communication. Loar cases demonstrate that exact similarity is consistent with communicative luck. Moreover, BEER illustrates that the social environment of an exchange can affect whether knowledge-yielding communication occurs. So no content relation by itself will be sufficient. ${ }^{16}$

However, as a necessary condition for knowledge-yielding communication a similarity requirement seems plausible. If two interlocutors assign completely different and unrelated meanings to one another's utterances then, it might be thought, their exchanges will not support the acquisition of knowledge (certainly not knowledge that can be labeled "testimonial" without stretching the concept beyond its limits). At the very least, a plausible approach to knowledge-yielding communication should explain the appeal of content similarity conditions, since they are accepted by so many theorists as a condition on communicative success. The main problem is that simply postulating a similarity requirement in this context is uninformative. It is not clear what dimensions or degrees of similarity would be necessary for knowledge-yielding communication. ${ }^{17}$ A satisfactory approach should, if it is to capture the widespread intuition that successful communication requires at least some level of coordination between interlocutors, rule out cases in which interlocutors assign completely unrelated meanings to one another's utterances. However, if the account is to be interesting and informative it should do so without explicit appeal to the notion of content similarity, as the relevant similarity relation is an important part of what we need to account for.

of co-reference (Onofri (forthcoming)), for successful communication. There are independent reasons to be skeptical of such approaches. For example, Hawthorne and Manley (2012) provide reasons to doubt that knowledge of reference is required. And Peet (2018) argues for the possibility of testimonial knowledge without knowledge of what is said.

16 Note that if Molly was absent in BEER knowledge-yielding communication would not have occurred. Yet the propositions entertained would be equally similar along all the relevant dimensions to the propositions entertained in BEER.

17 Indeed, as an anonymous referee points out, since we are not strictly concerned with knowledge through testimony it is unclear what principled reason there could be for maintaining a similarity requirement at all. I am sympathetic to this concern, and my final account makes no mention of content similarity. However, it is predicted by my positive account that, as it happens, knowledge-yielding communication will be vanishingly rare or impossible in cases where interlocutors entertain unrelated contents. This explains the common intuition that successful communication requires content similarity. 


\section{Communicative Luck}

The preceding discussion has provided us with several criteria a theory of knowledge-yielding communication must satisfy. A satisfactory approach will rule out communicative luck. It will allow for slight variation in meaning, whilst ruling out radical variation in meaning. And it will be allow for the social environment of an exchange to affect whether knowledge-yielding communication has occurred.

Knowledge-yielding communication was introduced as the minimal relation which obtains either when a communicative exchange results in the acquisition of knowledge, or when an audience's failure to acquire knowledge is due to some factor independent of the communicative exchange itself (e.g. the speaker's dishonesty). We can thus develop a promising account of knowledge-yielding communication by considering the conditions under which a feature of the communicative exchange itself may prevent the audience from gaining knowledge. The result is a view of knowledge-yielding communication modeled on knowledge itself.

An agent knows that $\mathrm{p}$, roughly, when they have a non-lucky non-deviant true belief that $\mathrm{p}$ (where "deviantly formed belief" is taken to include unjustified belief and belief which is rendered true or safe in the wrong way). Thus, in order for knowledge-yielding communication to fail the communicative exchange must be such as to render any belief it produces false, lucky, or deviant. The only way for the communicative exchange itself to render the audience's belief false would be for the speaker and hearer to entertain propositions with different truth values (otherwise the speaker's unreliability will explain the inability of the audience to gain knowledge). That is, we are considering the way in which the speaker's representational intention, and the audience's representation of the speaker as having presented a particular proposition as true, must be related in order for the audience to gain knowledge. The only way a defect in this relation could explain the audience's false belief would be for it to prevent coordination on truth values. If the hearer forms a false belief when there is successful coordination on truth values, then the speaker must intend a false proposition (either through dishonesty or incompetence). But in this case the salient explanation for the audience's false belief will be the speaker's defective intention. Even if the interlocutors had coordinated perfectly the audience would have still formed a false belief. Likewise, the only way for the communicative exchange to render the audience's belief lucky or deviant would be for the coordination to occur deviantly or as a matter of luck. This suggests that knowledgeyielding communication is simply non-lucky non-deviant coordination on truth values.

By treating knowledge-yielding communication as non-lucky non-deviant coordination on truth values we are able to satisfy the criteria outlined above. I will focus here on the notion of communicative luck, as this notion alone is able to do most of the relevant work. I will return to the issue of deviant communication in $\$ 6$. The basic anti-luck approach is as follows:

BASIC LUCK : In cases of knowledge-yielding communication 1) a speaker attempts to communicate some proposition, ${ }^{18}$ and an audience understands the speaker to be communicating

18 For my purposes it does not matter how we individuate propositions. They can be thought of as coarse grained entities representable as sets of possible worlds, or more fine grained structured entities. 
some proposition, ${ }^{19}$ 2) the interlocutors have representational states with identical truth values, 3) it is not a matter of luck that (2) is satisfied. ${ }^{20}$

Condition (2) requires some explanation. On the rough picture of communication I am presupposing a speaker has a communicative intention, which is representational in the sense that it attaches to some proposition - the object of their intention. The hearer then represents the speaker as having asserted some proposition. In doing so they have a representational state corresponding to the perceived content of the assertion. ${ }^{21}$ These are the representational states at issue in (2). For them to correspond in truth value is for the propositional content of each state to correspond in truth value.

It is clear that BASIC LUCK deals with the issue of communicative luck. However, it is less clear how it helps us with our other criteria. In particular, BASIC LUCK seems to allow for knowledge-yielding communication in cases where the interlocutors entertain completely unrelated propositions. I will argue that, when properly understood, (3) cannot be satisfied in such cases. If the propositions entertained by the speaker and hearer are not related in the right way then it will be a matter of luck that their representational states correspond in truth value. In order to see this we must unpack the relevant notion of luck. ${ }^{22}$

\subsection{Modal Instability}

The characteristic feature of lucky events is a feeling of instability - a lack of secure foundation. Lucky events seem to float free from the world of expectation, explanation, and prediction. It is the task of a theory of luck to account for this felt instability in a precise way. The modal view developed by Pritchard (2005) is currently the most influential approach to luck. It is, thus, a natural starting point. Pritchard gives the following as a condition on luck:

MAL: If an event is lucky, then it is an event that occurs in the actual world but which does not occur in a wide class of the nearest possible worlds where the relevant initial conditions for that

19 I wish to remain neutral on what it takes for a hearer to understand a speaker to be asserting a proposition p. It may involve believing that the speaker intended to communicate $\mathrm{p}$, or perhaps a perception like experience of the speaker as having said p. It does seem clear that neither the audience's interpretation nor the speaker's framing of their assertion can be unjustified or irrational if the exchange is to result in knowledge. Providing an account of the justification of interpretation and speech is part of the project of explicating the notion of non-deviant coordination. If the speaker's framing of their assertion or the hearer's interpretation is unjustified then, if they nonetheless coordinate, they will have done so in a deviant way. See $\$ 6$ for some brief comments on the non-deviance condition. A full account of the rationality of communication requires a more extended treatment than can be provided here.

20 BASIC LUCK allows that knowledge-yielding communication is prevented in cases where the interlocutors coordinate on truth values, but easily could have failed to do so by entertaining different propositions in relevantly similar situations. It also rules out knowledge-yielding communication in cases where the actual propositions entertained only correspond in truth value as a matter of luck. However, it allows for knowledge-yielding communication in cases where the interlocutors entertain false propositions. In such cases, assuming the coordination on truth values is not lucky, it will be the falsity of the recovered proposition, not some communicative defect, which prevents knowledge acquisition.

21 It may be that hearers typically entertain several propositions, either simultaneously or in sequence before settling on a final interpretation. If there is a significant duration during which one misinterpretation persists before being corrected we might say that knowledge-yielding communication has failed to occur until the final interpretation has been reached.

22 Although I will be drawing on proposed analyses of luck I don't claim that luck is ultimately analyzable. Even if luck is unanalyzable, attempts at analysis are useful in that they illuminate the structure of certain forms of luck. 
event are the same as in the actual world.

Pritchard 2005: 125.

This condition captures the notion that lucky events easily could have failed to occur. The sense of instability is captured in terms of modal instability: lucky events do not occur in a stable manner within the relevant sector of modal space. We can develop an approach to knowledge-yielding communication based on the modal account of luck as follows:

MODAL LUCK: In cases of knowledge-yielding communication 1) a speaker attempts to communicate some proposition, and an audience understands the speaker to be communicating some proposition, 2) the interlocutors have representational states with identical truth values, 3) it could not easily have been the case that (2) fail to be satisfied. ${ }^{2324}$

MODAL LUCK has some initial promise. For example, in BEER Molly's presence and dispositions guaranteed Marie and Sam's coordination on truth values in all nearby worlds. If Molly was absent then there would have been nearby worlds in which Sam and Marie failed to coordinate on truth values. It also straightforwardly handles HEIGHT.

Unfortunately, this simple modal account faces two major problems. Firstly, it appears to allow for knowledge-yielding communication in cases in which interlocutors entertain completely unrelated propositions. As long as the propositions entertained are true at all nearby worlds then MODAL LUCK will be satisfied. This is an unacceptable result.

This problem is not, by itself, damning for the modal approach. Standard modal approaches to epistemic luck do not hold merely that an agent's belief is lucky if it could easily have been false. They hold that a belief is lucky if the agent could easily have formed a relevantly similar false belief via the same method. ${ }^{25}$ This modification is essential if such views are to make the correct predictions about cases such as the following.

CALCULATOR: Ben is using a malfunctioning calculator. The answers it provides are random. He instructs it to calculate $1867+8946$ and, by chance, it spits out 10813 (the correct answer). Ben comes to believe, on the basis of this, that $1867+8946=10813$.

Ben's belief is correct. But we do not want to label it knowledge. It seems clear that he believes truly only as a matter of luck. Yet, his actual belief is true in all nearby worlds. It is only by factoring in similar

23 When assessing the truth of (3) it is important to hold (1) fixed across all the worlds considered. Otherwise we get communicative luck when some event could easily have occurred which would have prevented the communicative exchange from taking place.

24 The modal account bears similarities to an approach to communicative success with general terms developed by Pagin (forthcoming) according to which such success requires that the intended and recovered propositions be such that they could not easily have differed in truth value. This is not quite the same as MODAL LUCK since it allows for the requisite form of success to occur as a matter of luck. For example, it would allow for lucky communicative success in Loar cases (with general terms). This is due to its formulation in terms of the propositions believed, rather than the representational states of the agents (which could have different propositions as objects in nearby worlds).

25 Views along these lines are provided by Williamson (2000), Manley (2007), and Pritchard (2007). 
13

situations in which the same method is employed (i.e. using the defective calculator), but a different belief is formed, that we are able to secure the result that his belief is luckily true.

A similar move can be made with respect to MODAL LUCK. If a speaker and hearer assign vastly different meanings to the same term then, even if they happen to coordinate on truth values in their actual exchange, they will fail to do so in relevantly similar exchanges. For example, suppose Pete gets confused between France and Poland. Sue tells Pete that Germany invaded France during the Second World War. Pete takes Sue to be telling him that Germany invaded Poland during the Second World War. Both propositions are true. And we may suppose that they are each true in all nearby worlds. However, Pete's belief still seems lucky. We can explain this as follows: given this mismatch in meaning assignment Pete and Sue would fail to coordinate on truth values in many similar situations. For example, if Sue told Pete that France was liberated by the Allies in 1944 then Pete would come to believe that Poland was liberated by the Allies in 1944. This is false. Thus, they would fail to coordinate on truth values. In light of this we should interpret the modal condition as failing whenever there are nearby cases in which some aspect of the linguistic or interpretative basis for the speaker's framing of their utterance or the audience's interpretation of the utterance remains fixed, and results in a failure of coordination on truth values. The basic thought here is as follows: safety theories of knowledge hold that, if an agent easily could have formed a false belief, given the method employed, then it will be a matter of luck if they believe truly. Likewise, if the interpretative basis for an exchange easily could have led to a failure of coordination, then any actual coordination will be lucky.

The second problem with MODAL LUCK is less easily treated: there are Loar cases which satisfy MODAL LUCK. Consider the following case presented by Peet (2017):

LOAR 2: Smith and Jones are unaware that the man being interviewed on television is someone they see on the train every morning. Smith says 'He is a stockbroker', intending to refer to the man on television; Jones recognizes that Smith is drawing upon their common knowledge that there is a salient man on the television screen, but seeing the similarity between the man on the television and the man they often see on the train he thinks that Smith, who he assumes also recognizes the similarity, is talking about the man they see on the train. Now Jones, as it happens, has correctly identified Smith's referent, since the man on television is the man on the train; but he has failed to understand Smith's utterance.

Peet, 2017, 381.

Conditions one and two are satisfied: Smith and Jones are both rational and entertain true propositions. Condition three is also satisfied: We can imagine that Smith's intention is stable - he could not easily have intended a different proposition. Moreover, if Jones had not noticed a similarity between the man on the train and the man on the TV he would not have taken Jones to be talking about the man on the train. The next best referent is the man on the TV, so he would have correctly taken Jones to be talking about the man on the TV. Thus, in the nearest worlds where he interpreted Smith differently he would have recovered a proposition with the same truth value. Yet, the proposition he does recover necessarily has the same truth conditions as the proposition Jones intended. On direct reference views it is simply the same proposition. And most Fregeans take singular terms to be rigid designators, so the mode of presentation under which the referent is entertained will determine the same individual in all worlds. Thus, there are no nearby worlds in which Smith and Jones have representational states which differ in 
14

truth value, and it is not obvious that any aspect of the basis for either Smith's framing of his assertion, or Jones's interpretation of his assertion, could easily have resulted in coordination failure in similar cases. ${ }^{26}$

This problem is not new. It is a version of a familiar problem, which was originally pressed by Lackey (2008) as an objection to Pritchard's modal account of luck. The problem is that there can be modally stable lucky events. Consider the following case (paraphrased from Lackey (2008, p 261)):

BURIED TREASURE: Sophie plans to bury all her treasure. Her criteria for the burial spot are, for sentimental reasons, that it be on the northwest corner of her island, and that it be a spot where rose bushes can flourish. There is only one spot which satisfies these criteria. So, she buries her treasure there.

One month later Vincent is looking for a place to plant a rose bush in memory of his deceased mother who loved both roses and the northwest corner of the island. He quickly locates the only patch of land on the northwest corner of the island where rose bushes can flourish. He begins digging and discovers Sophie's buried treasure.

Vincent is lucky to find the treasure. However, he finds it in the majority of nearby worlds in which he plants a rose bush. Thus, modal stability within the sphere of nearby worlds is not sufficient for the elimination of luck. ${ }^{27}$

\subsection{Mere Coincidence}

As previously noted, lucky events exhibit a form of instability: a lack secure foundations or robust explanation. The modal account of luck, by focusing on modal instability, goes a long way toward capturing this sense of instability. What Lackey's case makes salient is that modal instability is not the only form of luck generating instability. To make progress we must identify the form of instability which occurs in BURIED TREASURE. This is not hard to do: a core feature of BURIED TREASURE is that Vincent's digging up the treasure is explained by a coincidence: The fact that he and Sophie both plan to plant rose bushes. ${ }^{28}$

26 The Fregean could avoid this issue by denying that names rigidly designate. However, Jones will still form the following actualized belief alongside his non-actualized belief: the actual person we see on the train every day is a stockbroker. The same puzzle can be generated with respect to this belief, which is plausibly communication based (Blome-Tillmann (2017) observes that we can generalize standard Gettier cases in a similar way to generate problems for simple modal anti-luck conditions on knowledge).

27 As an anonymous referee points out, not everyone shares the intuition that Vincent's discovery is lucky. Pritchard (2014), for example, holds that it is merely accidental. This does not undermine the point I am making in this paper however. The important point is that there is some luck-like instability in the event. Such instability is incompatible with knowledge: if it is a mere accident that a belief is true then it does not constitute knowledge. If one were to double down and hold that a belief constitutes knowledge whenever it is non-deviant and non-lucky in the modal sense, allowing for accidentally true beliefs to constitute knowledge, then there is little basis for denying that knowledge-yielding communication occurs in LOAR 2. Anybody who goes this way can embrace the simpler modal version of my account.

28 Broncano-Berrocal (forthcoming) provides a similar counter example to Pritchard's modal account of luck and is explicit about the role coincidences play in such cases. 
Coincidences involve two events corresponding (or, 'coinciding') in a particular way. For example, two acquaintances being in the same place at the same time, or two matching numbered balls being picked from an urn. However, not all correspondences are mere coincidences. For example, if two matching balls are picked because the agent was looking for matching balls, and could see the numbers, then the correspondence would be no mere coincidence. The distinguishing feature of mere coincidences is that they do not admit of robust explanation. This resistance to robust explanation captures the feeling of instability mere coincidences generate. Moreover, the explanatory instability exhibited by coincidence is, as illustrated by BURIED TREASURE, consistent with modal stability.

Traditionally, the resistance of mere coincidences to robust explanation has been explicated in terms of coincidental events lacking a common cause (Owens (1992)). However, as Lando (2017) shows, the common cause approach is flawed. She provides the following case:

PIANOS: A boy is playing with a ball in the courtyard of an apartment complex. He throws the ball too high, and it bounces off of the balcony of one apartment, sails through the air, bounces onto the balcony of another apartment, and finally falls to the ground. On each of the two balconies sits a grand piano. As the ball lands on the first balcony it strikes a note on the first piano, and as the ball lands on the second balcony, it strikes a note on the second piano. On each of the two pianos, the note struck is the high A.

Lando, 2017, 135.

The fact that the ball struck the same note on each piano is a mere coincidence. However, the boy's throw is a common cause of the ball's striking the high A on each piano. Moreover, the event of the striking of the first $\mathrm{A}$ is a cause of the striking of the second A. Thus, coincidental events can have common causes, and can be causes of one another.

Lando's diagnosis is as follows: In cases of mere coincidence two events exhibit a particular relationship: they correspond in a particular way. We are able to explain the individual features of each event in a robust way. However, there is more to explaining a relational fact than simply explaining the relata. We must explain why the facts are related in the way they are. That is, we must explain the relation itself. This is the type of explanation which is lacking in cases of mere coincidence. ${ }^{29}$

In PIANOS the striking of the first key, and the striking of the second key exhibit the following correspondence: the same note was struck on each keyboard. We can explain each event individually: we can explain why the ball hit the first high A, and we can explain why it hit the second high A. However, we cannot explain the relational fact that the ball hit the same note on each piano. The fact that the first

29 As an anonymous referee points out, it could be maintained that we have, in some sense, explained the relational fact once we have explained the relata. This worry is considered by Lando. She points out that it is that it may be OK to say that, in some sense, we have explained the relational fact by explaining the individual relata and conjoining them. The important point is that mere coincidences are distinguished from non-coincidences by the type of explanation we are able to give. In cases of mere coincidence we are stuck explaining the individual events and conjoining the explanations. In noncoincidental (or, non-merely coincidental) cases we can provide an independent explanation for the relational fact. We can explain the relational fact without simply stating and conjoining the explanations for the individual relata. The latter form of explanation is robust in a way in which the former is not. And it is the lack of such explanation which renders a correspondence merely coincidental (this issue is also discussed by Gamester (2018), who offers a similar solution). 
note struck was a high A is independent of the fact that the second note struck was a high A (and vice versa). Thus, the ball's hitting the same note on each piano is a mere coincidence.

It follows from Lando's account that coincidences can be modally stable: Suppose A and B are events which display a correspondence (such as each involving the same note being hit on a piano, or two matching balls being picked from an urn). Each event will have its own explanation. Suppose there are no nearby worlds in which the facts which explain A fail to obtain. And suppose the same is true of B. Then, even if there is no independent explanation for the relevant relational fact (e.g. that the same note was struck), the coincidence will occur in all nearby worlds. This allows us to provide a more complete diagnosis of both BURIED TREASURE and LOAR 2.

Vincent's discovery was lucky because it was partly explained by a coincidence: the fact that he and Sophie both decided to dig in a place where rose bushes would flourish. These decisions were not related in the right way. The fact that Vincent decided to dig in a location where rose bushes could flourish had nothing to do with the fact that Sophie decided to dig at such a location (and vice versa). This captures the feeling of instability we have regarding the case. Vincent's discovery of the treasure is unstable because, in an important sense, it lacks a robust explanation.

In LOAR 2 it is a matter of luck that Smith and Jones coordinate on truth values. Yet they do so in most nearby worlds. Their coordination is lucky because it is explained, in part, by a coincidence. It is true that Smith's thought is a partial cause of Jones's thought. Indeed, Smith's thought plays a role in explaining Jones's thought. The coincidence lies elsewhere: in the fact that each token thought refers to the same individual. The distinction between explaining the occurrence of a token thought and explaining its aboutness properties is important. If I see something cute it may cause me to have a thought about my son. My attention to the cute object plays a role in explaining my having a thought about my son. However, it plays no role in explaining the aboutness properties of my token thought. It is controversial what does explain the aboutness properties of my thought. The reference may be fixed, for example, by a description, an acquaintance relation, or some causal relation between a mental file and my son. But the explanation will not involve the cute object.

Smith's thought refers as a result, in some way, of his attention to the man on the TV. The reference might be fixed, for example, by a description (such as "the man on the TV"), his direct perceptual acquaintance with the individual, or some causal relation between a mental file and the man on the TV. Jones is also paying attention to the man on the television, and this attention plays a role in causing his belief. However, his attention to the man on the television does not play a role in determining the referent of his thought. Rather, his attention to the man on the television causes him to direct his attention elsewhere, toward the man on the train. It will be controversial what fixes the referent of Jones's thought. It may be fixed by some description such as "the man on the train", some memory based acquaintance relation, or some causal relation between the apparent stock broker and a mental file. Whatever story we give, the aboutness properties of Smith and Jones's token thoughts are explanatorily independent. We cannot provide a robust explanation the relational fact that Smith and Jones's token thoughts refer to the same individual. At best we can conjoin the individual explanations of the aboutness properties of each thought. 
To understand this better it is helpful to consider a contrasting example: A case in which it is no coincidence that the aboutness properties of two thoughts match. It is hard to give such an example whilst remaining neutral on matters of metasemantics, but consider the following example under the supposition that the aboutness properties of thoughts involving names are fixed by chains of deference originating in an initial baptism:

CHARLIE: Suppose Smith and Jones have a friend in common: Charlie. Charlie just got a promotion, and Smith wants to communicate this to Jones. So he says 'Charlie just got a promotion'. Jones then forms the belief that Charlie just got a promotion.

It is because Smith and Jones's uses of the word 'Charlie' have their origins in the same chain of use and deference, starting with an initial baptism, that their token 'Charlie' thoughts are about the same individual. To explain the relational fact that they have a thought about the same individual we do not need to give separate explanations of the aboutness properties of each token thought and conjoin them. We can explain this relational fact by pointing out that their uses of 'Charlie' are related in this way: their thoughts have the same aboutness properties because they result from the same chain of use. This stands in contrast to LOAR 2, where we cannot provide an independent explanation of the aboutness properties of Smith and Jones's token thoughts.

As mentioned in footnote eight, this provides a partial vindication of the Fregean thought that communicative success requires that the interlocutors' thoughts refer in suitably related ways. However, we do not need to build anything into the semantics of singular terms to explain the breakdown in communication. The explanation is given at the level of meta-semantics, and is consistent with coarse grained views of content. ${ }^{30}$

At this point one might wonder whether we can give an account of communicative luck purely in terms of coincidence. I am not optimistic. Just as luck generating instability seems to outstrip modal instability, it also seems to outstrip explanatory instability. Imagine a version of BEER where Molly is not present. Sam's belief would be luckily true. However, it is not clear that the correspondence in truth value between Sam and Marie's representational states would be a mere coincidence. After all, the truth of Marie's intended proposition partly explains the truth of the proposition Sam comes to believe. Marie intended to communicate that all the beer they had purchased had been consumed. Sam took her to be saying that all the beer at the party had been consumed. Each proposition was true, and the latter was partially dependent on the former. That is, it could not have been true without the former also being true. Moreover, the former significantly raises the probability of the latter. And any complete explanation of the latter truth will necessarily include an explanation of the former. Moreover, we cannot appeal to meta-semantic coincidence. Sam and Marie both entertain different propositions, they do not co-refer, and they are not intensionally equivalent. The only respect in which they directly correspond is in truth value. Thus, it does not seem that we can jettison the modal component of our anti-luck condition. Rather, we must add a "no coincidence" clause:

HYBRID LUCK: In cases of knowledge-yielding communication 1) a speaker attempts to

30 I have presented the anti-luck approach as a helping with Loar cases only insofar as they are a problem for knowledgeyielding communication. However, I believe the solution extends to other forms of communicative success insofar as such successes constitute achievements, and achievements in general preclude luck. 
communicate some proposition, and an audience understands the speaker to be communicating some proposition, 2) the interlocutors have representational states with identical truth values, 3) it could not easily have been the case that (2) fail to be satisfied, 4) (2) is not satisfied in virtue of a mere coincidence.

Building in the notion of coincidence also has a second advantage: it provides us with an additional restriction on meaning mismatch between speaker and hearer. For HYBRID LUCK to be satisfied it will usually be required that the correspondence in truth value between $p$ and $q$ be non-coincidental. Their truth values will need to be explanatorily connected in the right way (i.e. the truth or falsity of one will feature in the explanation for the truth or falsity of the other, or else their truth values will have a common explanation). This will not be the case when $p$ and $q$ are completely unrelated. Thus, we capture a second sense in which knowledge-yielding communication requires content similarity.

On the resulting view knowledge-yielding communication will usually break down when it is a mere coincidence that the propositions entertained by the speaker and hearer correspond in truth value. This will be the case even when each proposition is true in all nearby worlds, and it will be the case even when some third party is present so safeguard against a lack of coordination in truth value. ${ }^{31}$ For example, if we were to produce a version of BEER in which Marie somehow took Sam to be asking whether there was any beer left at a different completely unrelated party, and asserted "there isn't any beer left" on the basis of this knowledge, then we would be able to predict Sam's failure to acquire knowledge, even given Molly's presence and dispositions.

\section{The Problem of Strange and Fleeting Communication}

We now have an account of knowledge-yielding communication which solves all the problems we identified for the simple and content similarity views. HYBRID LUCK captures the inconsistency of knowledge-yielding communication with luck. It allows for slight variation in meaning assignment between interlocutors. But, at the same time, it predicts that radical divergence in meaning precludes knowledge. Moreover, it allows us to capture the ways in which the social environment in which an exchange takes place can affect the occurrence of knowledge-yielding communication. ${ }^{32}$

However, as noted in $₫ 5$, luck is not the only factor capable of undermining knowledge. If a belief is true in a deviant way then, even if it is non-lucky, it will fail to constitute knowledge. This is illustrated by what Greco (1999) calls 'the problem of strange and fleeting processes'; the problem that utterly bizarre processes, not of the sort we would normally take to support knowledge, can lead agents to have reliably true beliefs. The problem is illustrated by the following cases (from Plantinga (1993) and Pritchard (2012)):

31 Importantly, safeguarding against lack of coordination is not the same as positively causing coordination. As we will see in $\$ 6$, there are cases in which HYBRID LUCK is satisfied despite the propositions entertained by each interlocutor being unrelated. These cases involve a third party who not only safeguards against miscommunication, but positively brings about the coordination.

32 I don't claim that modal and explanatory instability exhaust the forms of instability which can render an event lucky. By further investigating the notion of luck we will be able to better understand the ways in which interlocutors must relate in order for knowledge-yielding communication to occur. However, I will not go beyond HYBRID LUCK here, as we already have enough to solve the problems we encountered with the simple view. 
BRAIN: Sandy has a brain lesion. He has not visited a doctor, nor has he experienced headaches or any of the other symptoms we would normally associate with brain lesions. Nonetheless, he believes that he has a brain lesion. This is because he has an unusual type of brain lesion which causes its victims to believe they have a brain lesion, even if they lack any additional evidence that they have a brain lesion.

TEMP: Temp forms his beliefs about the temperature in the room by consulting a thermometer. His beliefs, so formed, are highly reliable, in that any belief he forms on this basis will always be correct. Moreover, he has no reason for thinking that there is anything amiss with his thermometer. But the thermometer is in fact broken, and is fluctuating randomly within a given range. Unbeknownst to Temp, there is an agent hidden in the room who is in control of the thermostat whose job it is to ensure that every time Temp consults the thermometer the "reading" on the thermometer corresponds to the temperature in the room. Pritchard (2012), 260.

In BRAIN Sandy's belief is true, and its truth is not a matter of luck. However, it does not constitute knowledge, as it is formed in a deviant way. In TEMP Temp's belief is true, and its truth is not a matter of luck. Moreover, Temp's belief is formed in a non-deviant way. However, it is rendered non-lucky in a deviant way. The lesson here is that only certain kinds of reliable process are capable of yielding knowledge. In order to constitute knowledge one's belief must be true and safe in the right way. For example, it has been postulated that, in order to constitute knowledge one's safe true belief must be explained by the exercise of one's cognitive abilities (Greco (1999), Sosa (2007), Pritchard (2012), Broncano-Berrocal (forthcoming)), be explained by the proper functioning of one's cognitive systems (Plantinga (1993), Graham (2016, forthcoming)), or be explained in a characteristic or normal way (Peet and Pitcovski (2018)).

A similar problem arises with respect to knowledge-yielding communication: HYBRID LUCK can be satisfied in the wrong way. Consider the following example:

COORDINATION DEMON: The coordination demon has a strange habit. It spends its life guaranteeing that interlocutors coordinate on truth values. It selects two victims, waits until they are about to communicate, and then uses its mind reading powers to come to know both what proposition is intended by the speaker, and what proposition will likely be recovered by the audience. Its action from then on depends on whether the propositions entertained by the speaker and hearer match in truth value. If they do match in truth value then, no matter how bizarrely unrelated the propositions are, the demon does nothing. However, if they don't match in truth value, then the demon changes the internal wiring of the audience's brain so that they interpret the speaker has having said something with the same truth value as the speaker's intended proposition (this proposition may, but need not be related to the proposition the speaker intends).

This situation might play out in different ways, not all of which are problematic. For example, consider the case in which the demon is present, but does not intervene because, despite entertaining completely unrelated propositions, the thoughts of two interlocutors correspond in truth value. Knowledge-yielding 
communication has not occurred in this situation. Yet, the agents could not easily have had representational states which differ in truth value. Moreover, it might be thought non-coincidental that their thoughts correspond in truth value, as the demon would guarantee that they match in truth value. However, this is a mistake. The actual fact that their thoughts correspond in truth value is explained by a coincidence. The demon played no role in bringing about this state of affairs. The demon might naturally think "wow, it is lucky that I didn't have to intervene in this situation". So, when the demon does nothing we are able to straightforwardly capture the audience's failure to acquire knowledge in by appeal to HYBRID LUCK.

More problematic are cases in which the demon does have to intervene. Consider the following development: Bjorn intends to communicate that Obama is the current president. Berit gets mixed up between Obama and Trump, and would interpret Bjorn as asserting the proposition most of us would express by saying "Trump is the current president". The coordination demon intervenes, re-wiring Berit's brain so that she now takes "Obama" to refer to "the Great Barrier Reef", and "the president" to mean "immune to pollution". So, she ends up entertaining a proposition which is false, and thus corresponds in truth value to the proposition intended by Bjorn. Knowledge-yielding communication has not occurred in this case, yet HYBRID LUCK is satisfied. ${ }^{33}$

This failure of knowledge-yielding communication has nothing to do with luck though. Bjorn and Berit's coordination on truth values was brought about intentionally by the coordination demon. This illustrates that the elimination of communicative luck is not, by itself, sufficient for knowledge-yielding communication. The problem here parallels the problem of strange and fleeting processes: coordination must not only be reliable, it must also be explicable in the right way. A full account of knowledgeyielding communication would, thus, include an account of the admissible processes which can underlie coordination. It is natural, at this juncture, to turn to sophisticated reliabilist approaches to knowledge, such as proper functionalism, virtue reliabilism, or normality approaches. For example, we might maintain that coordination must arise from the proper functioning of the interlocutors' cognitive systems, and perhaps the communicative and linguistic norms which have developed to support communication. We might maintain that knowledge-yielding communication must be explicable in terms of the interlocutors' social, linguistic, and epistemic abilities. Or we might simply maintain that interlocutors must coordinate in a characteristic or normal way. Any such approach would allow us to deny that the coordination demon's meddling is able to support knowledge-yielding communication.

\section{Conclusion}

If two interlocutors communicate in such a way that the audience is unable to form a true, non-lucky, and non-deviant communication based belief, then the audience will not be able to gain communication based knowledge. When their belief is true, non-lucky, and non-deviant, it will constitute knowledge. This suggests that knowledge-yielding communication occurs whenever two or more interlocutors

33 It might be thought that COORDINATION DEMON can be captured by appeal to coincidence. After all, the fact that Obama is not the president is explanatorily unrelated to the fact that the great barrier reef is not immune to pollution. However, the fact that Bjorn and Berit's actual thoughts correspond in truth value is not, in this case, explained by the truth of the particular propositions they entertain. This relational fact can be fully and robustly explained without ever mentioning the contents of their token thoughts. The coordination demon's presence explains the correspondence in truth value without the need to mention the interlocutors' token thoughts. 
coordinate on truth values in a non-lucky and non-deviant way. I explicated the notion of communicative luck in modal and explanatory terms. The resultant view allowed us to capture the consistency of knowledge-yielding communication with communicative imprecision, and to capture, in an informative way, the sense in which interlocutors must entertain similar contents if communication is to succeed. Moreover, we were able to diagnose the problem Loar cases raise for knowledge-yielding communication without building anything into the semantics of singular terms. This solution generalizes to other forms of communicative success (such as understanding, which is commonly thought to be undermined in Loar cases) insofar as these other forms of success constitute cognitive or social achievements, as such achievements are inconsistent with intervening luck. ${ }^{34}$

\section{Bibliography}

Audi, R. 1997. The Place of Testimony in the Fabric of Knowledge and Justification. American Philosophical Quarterly 34 (4). 405-422.

Barnett, D. 2015. Is Memory Merely Testimony from One's Former Self? Philosophical Review. 124 (3). 353-392.

Blome-Tillmann, M. 2017. Sensitivity Actually. Philosophy and Phenomenological Research. 94 (3). 606-625.

Broncano-Berrocal, F. Forthcoming. Purifying Impure Virtue Epistemology. Philosophical Studies. 1-26.

Bezuidenhout, A. 1997. The Communication of De Re Thoughts. Noûs. 31(2). 197-225.

Bezuidenhout, A. 2002. Truth-Conditional Pragmatics. Noûs. 36 (16). 105-134.

Byrne, A., Thau, M. 1996. In Defence of the Hybrid View. Mind.105 (417). 139-149.

Carston, R. 2002. Thoughts and Utterances: The Pragmatics of Explicit Communication. Oxford: Blackwell.

Evans, G. 1989. The Varieties of Reference. Oxford University Press.

Fraser, R. 2016. Risk, Doubt, and Transmission. Philosophical Studies 173. 2803-2821.

Gamester, W. 2018. Truth: explanation, success, and coincidence. Philosophical Studies 175 (5). 1243-1265. Goldberg, S. 2007. Anti-Individualism: Mind and Language, Knowledge and Justification. Cambridge University Press.

Graham, P. 2016. Against Actual-World Reliablism: Epistemcally Correct Procedures and Reliably True Outcomes, In Fernandez (ed) Performance Epistemology: Foundations and Applications. Oxford University Press. 83-106.

Graham, P. Forthcoming. Normal Circumstances Reliabilism. Philosophical Topics.

Greco, J. 1999. Agent Reliabilism. Philosophical Perspectives. 13. 273-296.

Hawthorne, J., Manley D. 2012. The Reference Book. Oxford University Press.

Heck, R. 1995. The Sense of Communication. Mind. 104 (413). 79-106.

Heck, R. 2002. Do Demonstratives Have Senses? Philosopher's Imprint 2 (2). 1-33.

Lackey, J. 1999. Testimonial Knowledge and Transmission. The Philosophical Quarterly. 49 (197). 471-490.

Lackey, J. 2008. What Luck Is Not. Australasian Journal of Philosophy. 86 (2). 255-267.

Lackey, J. Forthcoming. The Duty to Object. Philosophy and Phenomenological Research.

Lando, T. 2017. Coincidence and Common Cause. Noûs 51. 132-151.

34 Acknowledgments: This paper has been in the works for a long time, and it has benefited from discussion with, and comments from too many people to name. However, I will do my best to name a few: Mark Bowker, Herman Cappelen, Alex Davies, Anna Drozdzowicz, Rachel Fraser, Lizzie Fricker, Mikkel Gerken, Olav Gjelsvik, Sandy Goldberg, Patrick Greenough, Josh Habgood-Coote, Torfinn Huvenes, Matt McKeever, Andrea Onofri, Peter Pagin, Kim Phillips Pedersen, Eli Pitcovski, Joey Pollock, and an anonymous reviewer for Philosophical Studies. This paper has also benefited greatly from the discussion it received when presented at the University of St Andrews 'Testimony in Context' workshop, the University of Hamburg 'New Trends in Epistemology' workshop, and the ConceptLab work in progress seminar at the University of Oslo. I thank the audiences who were present at these events, and the organizers. 
Leonard, N. Forthcoming. The Transmission View of Testimony and the Problem of Conflicting Justification. American Philosophical Quarterly.

Loar, B. 1976. The Semantics of Singular Terms. Pbilosophical Studies. 30 (6). 353-377.

MacFarlane, J. 2005. Knowledge Laundering: Testimony and Sensitive Invariantism. Analysis. 65 (286). 132-138.

MacFarlane, J. 2016. Vagueness as Indecision. Proceedings of the Aristotelian Society 90. 255-283.

Manley, D. 2007. Safety, Content, Aprioity, Self-Knowledge. The Journal of Philosophy 104. 421-441.

Onofri, A. Forthcoming. The Publicity of Thought. The Philosophical Quarterly.

Owens, D. 1993. Causes and Coincidences. Cambridge University Press.

Pagin, P. 2008. What is Communicative Success? Canadian Journal of Philosophy. 38. 85-116.

Pagin, P. Forthcoming. When Does Communication Succeed? The Case of General Terms. In Teresa

Marques and Åsa Wikforss (eds.), Shifting Concepts. Oxford University Press.

Paul, M. 1999. Success in Referential Communication. Philosophical Studies Series Vol. 80,

Dordrecht, The Netherlands: Kluwer Academic Publishers.

Peet, A. 2017. Referential Intentions and Communicative Luck. Australasian Journal of Philosophy 95 (2). 379-384.

Peet, A. 2018. Testimonial Knowledge without Knowledge of What is Said. Pacific Philosophical Quarterly 99 (1). 65-81.

Peet, A. Pitcovski, E. 2017. Lost in Transmission: Testimonial Justification and Practical Reason. Analysis. 77 (2). 336-344.

Peet, A. Pitcovski, E. 2018. Normal Knowledge: Towards an explanation based theory of knowledge.

The Journal of Philosophy 155 (3). 141-157.

Plantinga, A. 1993. Warrant: The Current Debate. Oxford University Press.

Pritchard, D. 2005. Epistemic Luck. Oxford University Press.

Pritchard, D. 2007. Anti-Luck Epistemology. Synthese 158 (3). 277-297.

Pritchard, D. 2012. Anti-Luck Virtue Epistemology. The Journal of Philosophy. 109. 247-79

Pritchard, D. 2014. The Modal Account of Luck. Metaphilosophy 45 (4-5). 594-619.

Recanati, F. 1993. Direct Reference: From Language to Thought. Oxford: Blackwell.

Schoubye, A., Stokke, A. 2016. What is Said? Noûs 50 (4). 759-793.

Sosa, E. 2007. A Virtue Epistemology. Oxford: Clarendon Press.

Sperber, D., \& Wilson, D. 1986. Relevance: Communication and cognition. Oxford/Cambridge, MA:

Blackwell/Harvard University Press.

Weber, C. 2015. Indexical Beliefs and Communication: Against Stalnaker on Self-Location. Philosophy and Phenomenological Research. 90 (3). 640-663.

Williamson, T. 2000. Knowledge and its Limits. Oxford: Oxford University Press. 